\title{
A Meta-Analysis of the Relationship Between Emotional Intelligence and Academic Performance in Secondary Education: A Multi-Stream Comparison
}

\author{
Nicolás Sánchez-Álvarez ${ }^{1 *}$, María Pilar Berrios Martos ${ }^{2}$ and Natalio Extremera ${ }^{3}$ \\ ${ }^{1}$ Department of Basic Psychology, Faculty of Psychology, University of Málaga, Málaga, Spain, ${ }^{2}$ Department of Social \\ Psychology, Faculty of Psychology, University of Jaén, Jaén, Spain, ${ }^{3}$ Department of Social Psychology, Faculty of \\ Psychology, University of Málaga, Málaga, Spain
}

OPEN ACCESS

Edited by:

Carolina Gonzálvez,

University of Alicante, Spain

Reviewed by:

Carlos Salavera

University of Zaragoza, Spain

Christopher Thomas,

University of Texas at Tyler,

United States

*Correspondence: Nicolás Sánchez-Álvarez nsa@uma.es

Specialty section: This article was submitted to Educational Psychology, a section of the journal

Frontiers in Psychology

Received: 14 April 2020 Accepted: 08 June 2020

Published: 21 July 2020

Citation:

Sánchez-Álvarez N, Berrios Martos MP and Extremera N (2020) A Meta-Analysis of the

Relationship Between Emotional Intelligence and Academic Performance in Secondary Education: A Multi-Stream Comparison.

Front. Psychol. 11:1517. doi: 10.3389/fpsyg.2020.01517
This study was a quantitative meta-analysis of empirical research on the relationship between emotional intelligence (EI) and academic performance (AP) that included the three main theoretical models of El. We conducted a computerized literature search in the main electronic databases. Forty-four of an initial 3,210 articles met the inclusion criteria. With 49 effect sizes and a cumulative sample size of 19,861 participants, we found significant heterogeneity indices indicating a variety of results. In general, the results of this study indicated a significant effect of El on AP $(\bar{Z}=0.26)$. Average association between El and AP was higher in studies measured El as ability $(\bar{Z}=0.31)$, than studies measured El as self-report $(\bar{Z}=0.24)$, and self-report mixed El $(\bar{Z}=0.26)$. In the educational field, this meta-analysis provides information on the specific role of $E l$ as a function of used measures. Some practical implications are discussed.

Keywords: emotional intelligence, academic performance, secondary education, meta-analysis, instruments

\section{INTRODUCTION}

In the educational field, academic performance (AP) is the construct that has been studied most. Teaching, learning, and all the cognitive factors related to AP have been widely examined (Pellitteri and Smith, 2007). Recently, one of the most analyzed research lines concerns the influence of personality factors and personal skills on achievement of AP (Poropat, 2009; MacCann et al., 2019). In the last 20 years, a large portion of research has been guided by a recent theoretical focus on emotional abilities, specifically emotional intelligence (EI), which has been viewed as a key component of the factors that influence well-being as well as adaptive processes in specific contexts (Zeidner et al., 2012). Several reviews showed the relevance of EI as a personal resource associated with health outcomes (Martins et al., 2010), well-being (Sánchez-Álvarez et al., 2016), and even task performance (Miao et al., 2017). Likewise, literature reviews focused on analyzing the role of EI in AP have been published (Perera and DiGiacomo, 2013; MacCann et al., 2019). These studies showed significant effects of EI in predicting AP after controlling the effects of 
intelligence and personality traits. In addition, EI has emerged as a strong predictor in secondary education.

\section{Academic Performance}

Academic success or performance by students in educational centers is a key goal in the development of all educational programs. AP has been commonly measured through continuous exams or evaluations, with a general consensus about the most important aspects to evaluate, such as skills, and declarative and procedural knowledge (Ward et al., 1996). Although there is no common agreement for the evaluation of AP, measures of cognitive skills or declarative knowledge are the main factors evaluated (Perera and DiGiacomo, 2013), and the most commonly used indicators to measure AP are usually: Grade Performance Academic (GPA), Achievement Test (AT), Grade Average (GA), Academic Achievement (AA), Standard Assessment Test (SAT), and Teacher Ratings Academic (TRA) (Perera and DiGiacomo, 2013).

Recent empirical research in education regarding predictors of AP has focussed on intelligence, IQ, or personal cognitive abilities. This research movement has accumulated an extensive research literature on the measurement of cognitive intelligence (Ritchie and Tucker-Drob, 2018). Moreover, there are other personal skills that differ from traditional cognitive intelligence that could affect academic success (Furnham et al., 2009). Currently, there are several lines of research that analyse individual non-cognitive factors that increase the prediction of AP, which requires broader educational models that integrate personal and contextual factors (Gutman and Schoon, 2013). Other non-cognitive skills include attitude, motivation, personality traits, self-regulation, resilience, and social and emotional skills, which are beyond the academic skills that determine successful performance (Bowles and Gintis, 2007). Likewise, personal factors such as motivation and emotional self-regulation in the classroom are associated with school performance, that is, students who are more motivated and have greater skill to manage emotions to obtain higher academic qualifications (Pintrich and de Groot, 1990). Currently, an increasing number of studies have examined the role of emotional skills such as EI in AP.

\section{Emotional Intelligence}

Since the EI concept was first introduced in the scientific literature by Salovey and Mayer (1990), different EI models have been developed. Based on the measurement methods used, the different theoretical conceptions of EI can be grouped into three main streams: (stream 1) Mayer and Salovey (1997) four branch ability model of EI, which defines ability EI as having four components, including the capacity to perceive, value, and express emotions accurately; the ability to access and generate feelings that facilitate thinking; the ability to understand emotions and emotional awareness; and the ability to regulate emotions and promote emotional and intellectual growth; (stream 2) cognitive emotional abilities three-branch self-perception model of Salovey and Mayer (1990), self-report EI proposes the existence of a continuous reflexive process associated with one's mood; (stream 3) cognitive emotional competences and other non-cognitive features like personal skills, motivation, and social aspects is conceived how EI mixed model (Goleman, 1995; Mayer and Salovey, 1997; Petrides et al., 2004a; Bar-On, 2006).

The ability EI stream (stream 1), also defined as EIperformance, is the conception of EI that seems to have the most similarity to AP, because EI is measured by exercises and problems to assess emotional ability, just as exams are used to measure AP in schools. On the other hand, because ability EI is assessed in a similar way to AP, students with higher levels of EI-performance could better manage stress related to exams, resulting in better AP (Brackett and Salovey, 2006). At the same time, students with inadequate or poor emotional skills will have school maladjustment, interpersonal problems that affect their anxiety (Rivers et al., 2012), and/or a lack of social support from their peers that affects their AP (Mestre et al., 2006). The instruments developed to assess ability EI, the Mayer, Salovey, and Caruso Emotional Intelligence Test (MSCEIT) (Mayer et al., 2002) and the Multifactor Emotional Intelligence Scale (MEIS) (Mayer et al., 1999), have objective criteria for correct and wrong answers.

The self-report EI stream (stream 2), based on selfperception of one's emotional skills, assesses a person's subjective emotional abilities. This means that each individual indicates their level of EI according to their previous experiences and their level of self-esteem, including the mood in which they find themselves when completing the EI self-report scale (Davies et al., 1998). This type of measure is usually related to well-established personality factors such as neuroticism, extraversion, agreeableness, openness, and psychoticism, and this connection can yield false correlations with performance and academic achievement (Gannon and Ranzijn, 2005). Representative self-report EI instruments include the Wong and Law Emotional Intelligence Scale (WLEIS) (Wong and Law, 2002), Trait Meta-Mood Scale (TMMS) (Salovey and Mayer, 1990), Schutte Emotional Intelligence Scale (SEIS) (Schutte et al., 1998; Saklofske and Zeidner, 2006), and Swinburne University Emotional Intelligence Test (SUEIT) (Palmer and Stough, 2001).

In the mixed EI stream (stream 3), the integration of different personal and social skills leads to overlapping effects with other factors that may influence AP. When evaluating personality variables, cognitive skills, and social-emotional traits together, one obtains a profile that may be more associated with the different skills that are implemented in an academic context. Therefore, students with better social-emotional traits, with high cognitive abilities (Shen and Comrey, 1997), and adaptive personality trait variables achieve better test scores (Pulford and Sohal, 2006; Poropat, 2009). Therefore, students with better adaptation to the school context will obtain better scores in AP than students with profiles less oriented toward academic adaptation. Representative measures of mixed EI include the Emotional Quotient Inventory (EQi) (Bar-On, 1997), Trait Emotional Intelligence Questionnaire (TEIQ) (Petrides, 2009), and Emotion Identification Skills (EIS) (Ciarrochi et al., 2008).

Each of the three main streams has contributed to research linking EI and AP, with heterogenous results, despite being evaluated with instruments developed under the same theoretical 
conceptions of EI. It is not surprising that EI is conceived from several theoretical approaches. A possible cause of the lack of consensus on the results may be the multitude of instruments to evaluate EI from the different theoretical approaches.

\section{Theoretical Linkages Between Emotional Intelligence and Academic Performance}

The EI literature has shown that individuals with a higher capacity to process information typically perform better on cognitive tasks (Saklofske et al., 2012). Interpersonal and intrapersonal skills are of great importance in secondary education, since it is a period that involves many social, contextual, and personal changes and stresses. During adolescence, the peer group is of great relevance to adolescents' emotional development and identity formation (Duncan et al., 2006; Eccles and Roeser, 2009), with immediate contexts such as the school environment being one of the most relevant (Monreal and Guitart, 2012). In this sense, the events and early experiences lived in the different contexts, the reactions and responses of adolescents to the different situations of risk and stress throughout their development, as well as the existence of resource vulnerability protection, are relevant and important to understanding individual differences between young people (Monreal and Guitart, 2012). Greater emotional regulation and a better process of adaptability are useful to cope with academic stress and achieve academic success (Saklofske et al., 2012). Interestingly, emotional perceptive people appear to be more strongly impacted by stress than their less perceptive counterparts, expressing higher levels of psychological distress (Ciarrochi et al., 2002). It is hypothesized that low perceptive people might ignore thoughts of daily hassles and therefore might be more likely to be confused about the experienced negative feelings showing less coherence between their levels of perceived stress and psychological maladjustment. Thus, people with high EI are more resilient, adapting more easily to changes, reacting better under stress conditions, and coping with difficulties in the form of challenges (Schneider et al., 2013). Finally, students with a better management of their emotions are happier and have better social relationships (Eryilmaz, 2011). In turn, having better interpersonal management is generally associated with higher social networks, as well as better friendships quality (Brackett et al., 2005). Similarly, having a greater social network in a classroom might stimulate an adequate social environment for better cooperative work, better group learning, greater support from classmates (Hogan et al., 2010), and better relationships with teachers (Di Fabio and Kenny, 2015). Together, both the academic climate involving classmates and professors, as well as a better predisposition of learning-oriented abilities might be associated with a greater AP (Brackett et al., 2011; Johnson, 2016). In summary, there are several plausible theoretical mechanisms that might explain the relationship between EI as a set of skills and optimal academic functioning in secondary education.

\section{Current Meta-Analysis}

Previous work has excluded studies conducted with instruments developed under other theoretical approaches of EI (Perera and
DiGiacomo, 2013), or has contemplated the role of EI in AP in a more global way and by levels (MacCann et al., 2019), making it difficult to compare the results between different instruments. The present study examined the association between EI and $\mathrm{AP}$, considering instruments developed from all the theoretical approaches to EI in studies conducted in secondary school students, as an educational level of greater relevance according to previous literature (Perera and DiGiacomo, 2013; MacCann et al., 2019). Our meta-analysis aimed to examine previous review studies, comparing the results by the main streams and EI instruments used in secondary education including native English and Spanish speakers. The current meta-analysis study was carried out to (1) asses the associations of AP and EI, hypothesizing that there will be a significant correlation between EI; (2) show the associations of different instruments used to assess EI based on three main streams and levels of AP; in line with previous studies, it was hypothesized that EI ability instruments would have a greater association with AP.

\section{METHODS}

\section{Literature Search}

We searched relevants studies of EI y AP on electronic database: PsychoINFO, MEDLINE, SCOPUS, PubMed, ISI Web of Science, Google Scholar, and ProQuest Dissertations and Theses. The search term (emotional intelligence) AND (academic performance OR academic achievement OR grades performance OR academic OR education OR school) AND (secondary level). We also reviewed specialized database journals of relevant papers. This review was conducted from June 2017 to January 2020.

\section{Inclusion Criteria}

Studies eligible were scanned titles and abstracts, and included in the review all those that referred to the above terms. To be included in the review, papers had to meet the following inclusion criteria for eligibility of studies (Lipsey and Wilson, 2000): (1) empirical study that provides data on the association between EI and AP; (2) minimum sample size at least 20 participants; (3) studies had to have been performed between 1999 and 2020 (January); published article and unpublished doctoral thesis without published and conference paper, (4) studies written in Spanish and English.

\section{Coding}

Following a Lipsey and Wilson (2000) : (a) country, (b) publication type, (c) design features, (d) measure used to asses EI, (e) AP index, (f) study sample size, (g) size of the association between key variables, (h) level of significance. Finally, extrinsic characteristics coded were results reporting the year and publication source (see Table A1).

\section{Statistical Analysis}

All data were conducted in R (Team, 2012), using the "stats" and "metaphor" packages (Viechtbauer, 2010). For the meta-analysis the technique by DerSimonian and Laird (1986) was used. The $Q$-value indicated heterogeneity among studies $(p<0.10)$, thus 
applied random effect models was used in the meta-analysis. Additionally, we quantified the effect of heterogeneity using $I^{2}$ (Higgins and Thompson, 2002). The $I^{2}$ value indicate proportion of inconsistency due to heterogeneity rather than chance. The effect size index was converted by Fisher $\mathrm{r}-\mathrm{Z}$ following the procedures recommended by Hedges and Olkin (1985). The categorical model between-class results were obtained through a goodness-of-fit statistic $Q_{b}$, and the within-class goodness-offit statistic $Q_{w}$. The statistic $Q_{w j}$ within-category heterogeneity is under the null hypothesis of within-category homogeneity.

\section{Publication Bias}

Publication bias was evaluated by rank correlation with Kendall's tau method, in which a significant correlation indicates

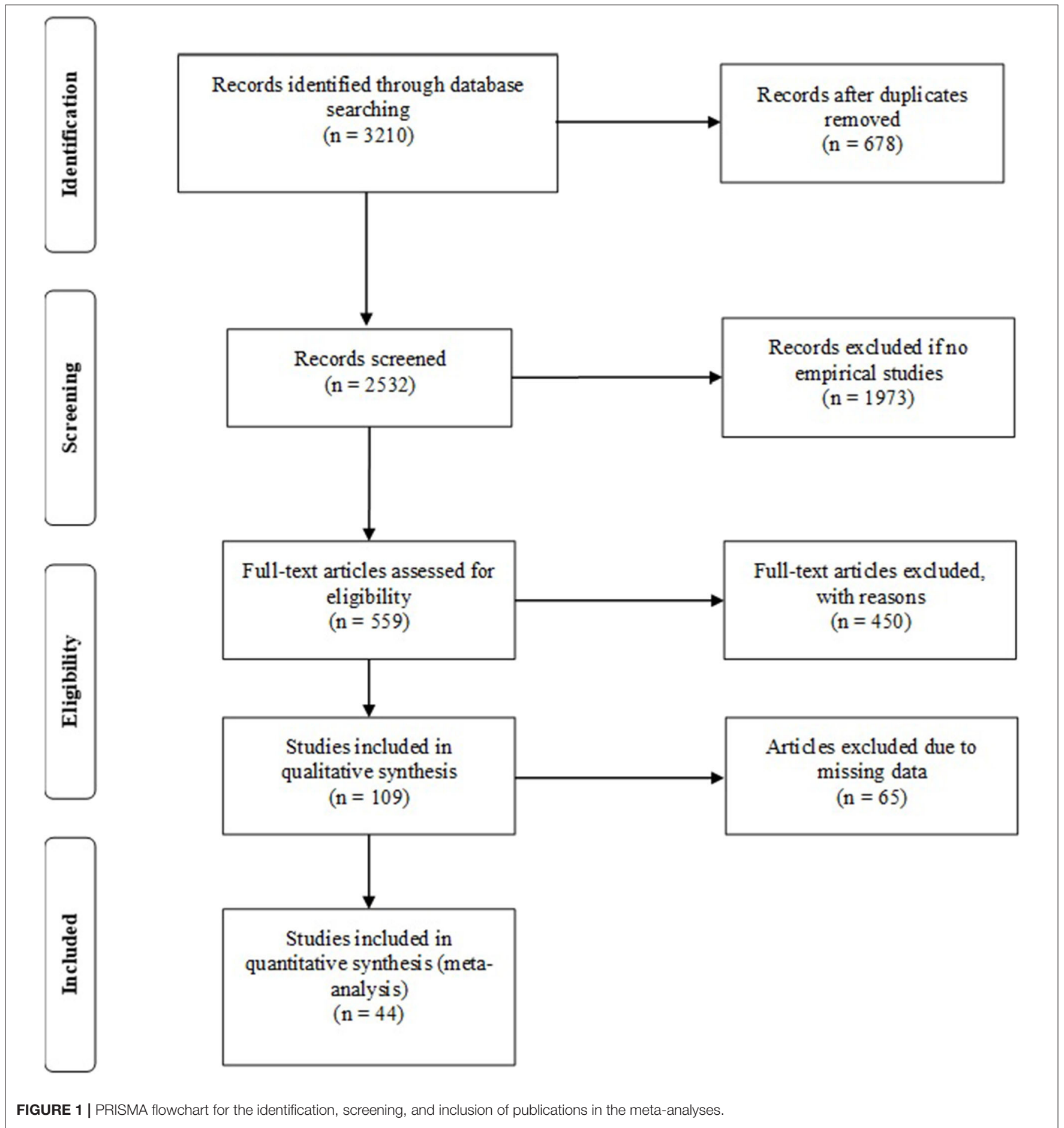


publication bias, and Egger's regression test asymmetry, in which significant asymmetry indicates publication bias (FernándezCastilla et al., 2019). The Egger regression test should not differ significantly $(z=-1.189, p=0.234)$, and the rank correlation yielded non-significant results $(T=0.03, p=0.243)$. Nonsignificant results showed symmetry and absence of publication bias. Regression tests and the funnel plot indicated a nonsignificant asymmetry, so the results showed no evidence of publication bias between EI and AP.

\section{RESULTS}

\section{Selected Studies}

The sample consisted of 3,210 studies, 678 were duplicate studies. Eventually, 1,973 did not correspond to association between EI and AP. They associated lack of personal distress and absence of mental disorder to higher levels of well-being. The full text of the remaining 559 articles were reviewed, obtaining 44 items that were selected and evaluated more deeply (see Figure 1).

\section{Study Characteristics}

The articles included in the meta-analysis showed a closed association between target variables. The overall sample consisted of 19,714 participants, and the mean age was of 15.82 years. Several studies included some scales for assessing EI, obtaining 49 effect sizes. The studies included were conducted in 16 countries, with the largest number conducted in the US (14 studies).

\section{Association of El and AP}

The main results of this study indicated that the association between EI and AP had a significant low to moderate cumulative effect $(\bar{Z}=0.26$; CI from 0.14 to 0.38$)$. A DerSimonian test and Laird's random effect showed statistical evidence of heterogeneity $(Q=1,206.16, p<0,001)$, indicating a greater variance of effect sizes between studies than anticipated by chance. In addition, the $I^{2}$ estimated of $96 \%$ suggests a high proportion of variation between samples.

\section{Main El Streams}

The categorical model test that examined the subgroup model results intra-group showed statistical evidence of heterogeneity $\left(Q_{b}=0.39, p=0.540\right)$. The $Q_{w}$ statistics revealed that the model was misspecified $\left(Q_{w}=1,205.77, p<0.001\right)$. Therefore, significant differences were found between the effect sizes, indicating heterogeneity within each category (see Table 1). The ability stream showed lower levels of heterogeneity $\left(Q_{w j}=24.16\right.$, $p<0.012)$, with smaller variation between scores $\left(I^{2}=54 \%\right)$ obtained between the different studies that used ability stream instruments. When examining the effect size results by grouping the EI instruments by main streams, we found larger effect sizes for those studies that used instruments based on the ability EI stream $(\bar{Z}=0.31)$. At the same time, the degree of inconsistency between studies that used instruments based on the ability EI stream was lower $\left(I^{2}=54 \%\right)$ than in the other groups of studies (self-report EI stream $I^{2}=99 \%$; mixed EI stream $I^{2}=92 \%$ ).
TABLE 1 | Olkin and Pratt weighted average (Z), effect size number (K), homogeneity test $\left(Q_{w j}\right)$, and the degree of inconsistency $\left(I^{2}\right)$ between El main stream.

\begin{tabular}{lcccccc}
\hline El stream & $\boldsymbol{N}$ & $\overline{\boldsymbol{Z}}$ & $\boldsymbol{K}$ & $\boldsymbol{Q}_{\boldsymbol{w j}}$ & $\boldsymbol{P}$ & $\boldsymbol{I}^{\mathbf{2} \%}$ \\
\hline Ability (stream 1) & 2,644 & 0.31 & 12 & 24.16 & 0.012 & 54 \\
Self-report (stream 2) & 9,529 & 0.26 & 7 & 869.24 & 0.001 & 99 \\
Mixed (stream 3) & 7,628 & 0.24 & 25 & 312.37 & 0.001 & 92 \\
\hline
\end{tabular}

$Q_{w}=1205.77, p<0.001$.

$Q_{b}=0.39, p<0.100$

TABLE 2 | Olkin and Pratt weighted average $(\bar{Z})$, effect size number (K), homogeneity test $\left(Q_{w j}\right)$, and the degree of inconsistency $\left(I^{2}\right)$ between El measure.

\begin{tabular}{lcccccc}
\hline EI measure & $\boldsymbol{N}$ & $\bar{Z}$ & $\boldsymbol{K}$ & $\boldsymbol{Q}_{\boldsymbol{w j}}$ & $\boldsymbol{P}$ & $\boldsymbol{I}^{\mathbf{2}} \%$ \\
\hline MSCEIT & 138 & 0.35 & 8 & 3.05 & 0.880 & 78 \\
EQ-i & 3,017 & 0.21 & 15 & 80.58 & 0.001 & 82 \\
TEIQUe & 2,675 & 0.18 & 8 & 92.30 & 0.001 & 92 \\
SUEIT & 452 & 0.22 & 2 & 0.63 & 0.426 & 58 \\
AMEIS & 205 & 0.14 & 1 & - & - & - \\
EIS & 1,936 & 0.40 & 5 & 62.89 & 0.001 & 93 \\
EQBI & 1,563 & 0.94 & 1 & - & - & - \\
MEIS & 39 & 0.50 & 1 & - & - & - \\
ESCQ & 380 & 0.17 & 1 & - & - & - \\
SSREI & 127 & 0.15 & 1 & - & - & - \\
TMMS & 5,268 & 0.17 & 2 & 12.17 & 0.001 & 91 \\
STEM-Y & 525 & 0.26 & 2 & 0.51 & 0.476 & 97 \\
PSM & 486 & 0.14 & 1 & - & - & - \\
EM & 1,799 & 0.02 & 1 & - & - & - \\
\hline
\end{tabular}

$Q_{w}=252.13, p<0.001$.

$Q_{b}=954.04, p<0.001$.

\section{Type of El Measure}

As shown in Table 2, the different instruments used to assess EI had differing levels of association with AP. Moreover, there was much variability in the scores obtained in studies using the same EI instrument. Only the MSCEIT $\left(Q_{w j}=3.05, p=\right.$ $0.880)$, SUEIT $\left(Q_{w j}=0.63, p=0.426\right)$, and Situational Test of Emotion Management for Youths (STEM-Y) $\left(Q_{w j}=0.51, p=\right.$ 0.476 ) measures did not show significant levels of heterogeneity between the effect sizes of the different studies. On the other hand, the largest effect sizes were observed in studies that used the Behavior Emotional Quotient Inventory (EQBI) $(\bar{Z}=0.94, K$ $=1)$, followed by the studies carried out with the MEIS $(\bar{Z}=0.50$, $K=1)$, EIS $(\bar{Z}=0.40, K=5)$, and MSCEIT $(\bar{Z}=0.35, K=8)$ instruments. At the same time, the lowest degree of inconsistency between studies that used the same instruments was found for the SUEIT $\left(I^{2}=58 \%, K=2\right)$, followed by the MSCEIT $\left(I^{2}=78 \%, K\right.$ $=8)$, and Emotional Quotient Inventory (EQ-i) $\left(I^{2}=82 \%, K=\right.$ $15)$, with the EQ-i being the most widely used instrument.

\section{Type of AP Measure}

Subgroup analysis was conducted to examine the variability in the scores obtained in studies using the same AP instrument (see Table 3). The highest degree of variability in the scores between 
TABLE 3 | Olkin and Pratt weighted average $(\bar{Z})$, effect size number $(K)$, homogeneity test $\left(Q_{w j}\right)$, and the degree of inconsistency $\left(I^{2}\right)$ between AP measure.

\begin{tabular}{lcccccc}
\hline AP measure & $\boldsymbol{N}$ & $\bar{Z}$ & $\boldsymbol{K}$ & $\boldsymbol{Q}_{\boldsymbol{w j}}$ & $\boldsymbol{P}$ & $\boldsymbol{I}^{\mathbf{2}} \%$ \\
\hline GPA & 11,623 & 0.28 & 30,00 & 246.68 & 0.001 & 88 \\
ACS & 205 & 0.14 & 1,00 & - & - & - \\
AA & 1,337 & 0.24 & 5,00 & 16.35 & 0.003 & 76 \\
ABE & 161 & 0.20 & 1,00 & - & - & - \\
AT & 165 & 0.12 & 1,00 & - & - & - \\
MA & 169 & -0.24 & 1,00 & - & - & - \\
GA & 2,168 & -0.01 & 2,00 & 0.49 & 0.485 & 99 \\
TRA & 254 & 0.23 & 2,00 & 1.90 & 0.168 & 47 \\
VSLECRA & 142 & 0.38 & 1,00 & - & - & - \\
WAEC & 1,563 & 0.74 & 1,00 & - & - & - \\
SAT & 139 & 0.07 & 1,00 & - & - & - \\
GCSE & 1,935 & 0.14 & 3,00 & 35.07 & 0.001 & 94 \\
\hline
\end{tabular}

$Q_{W}=300.48, p<0.001$.

$Q_{b}=955.71, p<0.001$.

studies using the same instruments was found for the GPA $\left(Q_{w j}=\right.$ $246.68, p<0.001)$, AA $\left(Q_{w j}=16.35, p=0.003\right)$, and GCSE $\left(Q_{w j}\right.$ $=35.07, p<0.001)$. Furthermore, the largest effect sizes were observed in studies using the WAEC $(\bar{Z}=0.74, K=1)$, followed by the studies using the VSLECRA $(\bar{Z}=0.38, K=1)$, and GPA $(\bar{Z}$ $=0.28, K=30$ ) instruments. Simultaneously, the lowest degree of inconsistency between studies using the same instruments was found for the TRA $\left(I^{2}=47 \%, K=2\right)$, followed by the AA $\left(I^{2}=\right.$ $76 \%, K=5)$ and GPA $\left(I^{2}=88 \%, K=30\right)$, with the GPA being the most widely used instrument.

\section{DISCUSSION}

The current study was designed to examine the relationship between EI and AP through meta-analyses comparing diverse main EI streams and instruments used in secondary education. Filling the gaps in previous meta-analytic research, our study provides new data, and expands past findings. After a literature review, 44 studies with 49 independent effect sizes based on 19,714 secondary school students were included in cumulative quantitative research on the link between EI and AP. Publication bias analysis showed that these findings are robust and reliable.

Regarding hypothesis 1 , we found a moderate significant cumulative effect between EI and AP, including measures of the three main EI streams, and diverse indicators of AP. These findings support previous research (Perera and DiGiacomo, 2013; MacCann et al., 2019) suggesting that EI levels are moderately associated with academic success, which suggests that knowledge of one's own and others' feelings, as well as the ability to solve adaptive problems, provides an essential basis for academic learning (Zeidner and Matthews, 2016). Additionally, these results show that EI is a personal resource with an important influence in the academic field, as a process of adaptation to the environment (Zeidner et al., 2012). EI has a dual role; on the one hand, it has intrapersonal affective influences on aspects related to AP, such as motivation and self-regulation.
On the other hand, interpersonal skills increase social networks in the academic environment, improving teamwork, which is so important in secondary education level. Teaching staff, through workshops can develop emotional skills to help improve mental health and interpersonal aspects, which is supported by previous literature. Current programs aim to reduce aggressive behavior and substance use; future programs should also target school performance. To deepen these interactions between emotional skills and relevant factors in AP, it would be interesting for future meta-analytical studies to focus on revealing and quantifying each of these links, especially those that are relevant at the secondary level, as it is a period full of changes, is very sensitive to risks, and involves searching for immediate well-being.

With respect to hypothesis 2 , we found differences in the levels of association of EI and AP as a function of the EI measures category. The results showed non-significant differences, with ability EI measures (Mayer and Salovey, 1997) showing a greater association with AP, followed by self-report EI (Salovey and Mayer, 1990), and finally the mixed EI stream (Bar-On, 2006). This higher index of association between EI measured with ability instruments and AP may be due to similarities with the tests used to obtain AP, as both of them use performancebased tests. In this sense it is possible this collinearity effect occurred because students who have good abilities to respond to performance tests will obtain high scores in both EI tests and tests that evaluate AP (Ogundokun and Adeyemo, 2010). At the same time, and contrary to other meta-analytical studies on EI (Martins et al., 2010; Sánchez-Álvarez et al., 2016), the most commonly used instruments in academic contexts are instruments developed from the mixed EI approach. Future studies should analyse in detail these effects of overlap and collinearity with personality and other aspects to obtain nonbiased findings. Previous review studies (Perera and DiGiacomo, 2013; MacCann et al., 2019) did not assess the impact of different measures of EI on the association with AP, so these findings provide relevant information for future studies. The results showed great heterogeneity within each instrument category, presenting large differences between different studies that used the same instrument to measure EI (Sánchez-Álvarez et al., 2016). This variability could be caused by moderating variables such as sex, IQ, and personality traits, that moderate the EI-AP association when the same instruments are used (Petrides et al., 2004b; Furnham et al., 2005). Furthermore, they may be due to variations in adaptations to different languages or variations due to cultural differences (Fernández-Berrocal et al., 2005; Ang and van Dyne, 2015). These results go beyond differences between the various instruments to evaluate EI, since they show differences despite using the same instrument. Although it is logical for each theoretical approach to develop and use its own instruments to analyse emotional skills, the results of this type of meta-analysis show the difficulties encountered when comparing the results of studies investigating this area of interest. This is certainly one of the sources of heterogeneity, and the consequent controversy about the results. To clarify this issue, it would be necessary for future studies to select instruments to evaluate emotional skills that have a robust trajectory and well-confirmed psychometric replicative properties in cross-cultural studies. Few studies have 
been conducted with Spanish-speaking samples. Therefore, more research is needed in Spanish and Latin American population.

The findings of this review should be considered with caution because there were several limitations. The current study was done without controlling for IQ, personality, and other variables that could influence the results. Other studies have been published in languages other than English and Spanish. On the other hand, EI integrates several dimensions, and this study did not take into account the individual associations that each of the dimensions of EI have with AP. It is possible that the associative effect of some dimensions of EI are greater than others, which implies that unifying all the dimensions of EI and analyzing the overall effect they have with AP could produce bias. Future studies should analyze each of the dimensions and their relationship with AP individually, and then compare them to analyze the differences.

These findings have several implications for research and application contexts. The school setting is one of the most important contexts for learning emotional skills and competencies (Zeidner and Matthews, 2016). EI training improves other associated issues, as well as improving performance. Developing emotional skills in early stages of adolescence (Herrera et al., 2020), will allow them to become consolidated personal resources to face risks and promote motivation oriented toward academic success and well-being. For this reason, this review study provides relevant information for the development of programs focused on increasing emotional skills in students, as well as providing tools for teachers and counselors, providing an empirical basis for the development of theoretical educational models oriented to AP. These findings cover the ages at which socio-emotional skills are most important, as well as relevant information for educators and teaching staff on the use of appropriate tools to assess EI in secondary education. We recommend that practitioners be cautious in choosing EI measurement instruments because of differences in their use. In the field of research, this meta-analysis

\section{REFERENCES}

Abdo, N. (2012). Academic Performance and Social/Emotional Competence in Adolescence. New York, NY: Yeshiva University.

Abdullah, M. C., Elias, H., Mahyuddin, R., and Uli, J. (2004). EI and academic achievement among malaysian secondary students. Pakistan J. Psychol. Res. 19, 105-121.

Abel, N. R. (2014). Trait Emotional Intelligence, Perceived Discrimination, and Academic Achievement among African American and Latina/O High School Students: A Study of Academic Resilience. Mankato, MN: Minnesota State University.

Ang, S., and van Dyne, L. (2015). "Conceptualization of cultural intelligence: definition, distinctiveness, and nomological network," in Handbook of Cultural Intelligence (New York, NY: Routledge) 21-33.

Aremu, O. A., Tella, A., and Tella, A. (2006). Relationship among emotional intelligence, parental involvement and academic achievement of secondory school students in Ibadan, Nigeria. Essays Educ. 18, $1-14$.

Bar-On, R. (1997). The Emotional Intelligence Inventory (EQ-I): Technical Manual. Toronto, ON: Multi-Health Systems.

Bar-On, R. (2006). The Bar-on model of emotional-social intelligence (ESI). Psicothema 18(Suppl.), 13-25. provides information on which future studies should be conducted, helping to clarify the different EI concepts and evaluation measures. Future studies would need to replicate these findings with a larger sample and more of the different EI measures, including variables that may influence AP.

In conclusion, the results of this study found great heterogeneity in the outcomes assessed, so the findings should be considered with caution. The results of this meta-analysis show a moderate association between EI and AP. Future research should explore how other variables influence this relationship, improving our understanding of EI and how it influences our lives. This meta-analytic study presents a quantitative review of the association between EI and AP globally and categorically, shedding light on the gaps in previous studies on the topic on adolescents. This study also shows the inadequacies in the review of studies in this field and provides guidelines to be followed in future empirical studies on AP. These discoveries are of great relevance in the explanatory models intended to predict academic success in secondary education.

\section{DATA AVAILABILITY STATEMENT}

The original contributions presented in the study are included in the article/supplementary material, further inquiries can be directed to the corresponding author/s.

\section{AUTHOR CONTRIBUTIONS}

All authors listed have made a substantial, direct and intellectual contribution to the work, and approved it for publication.

\section{FUNDING}

This work was supported by Instituto de Estudios Giennenses. Diputación Provincial de Jaén. Convocatoria 2018 (Ref. 2018.160.3340.45100).

Bowles, S., and Gintis, H. (2007). "Broken promises: school reform in retrospect," in Sociology Education A Critical Read, ed A. R. Sadovnik (New York, NY: Routledge), 53-70.

Brackett, M. A., Rivers, S. E., and Salovey, P. (2011). Emotional intelligence implications for personal, social, academic, and workplace success. Psychology 1, 88-103. doi: 10.1111/j.1751-9004.2010.00334.x

Brackett, M. A., and Salovey, P. (2006). Measuring emotional intelligence with the Mayer-salovery-caruso emotional intelligence test (MSCEIT). Psicothema 18(Suppl.), 34-41.

Brackett, M. A., Warner, R. M., and Bosco, J. S. (2005). Emotional intelligence and relationship quality among couples. Pers. Relatsh. 12, 197-212. doi: 10.1111/j.1350-4126.2005.00111.x

Chamundeswari, D. S. (2013). Emotional intelligence and academic achievement among students at the higher secondary level. Int. J. Acad. Res. Econ. Manag. Sci. 2, 178-187. doi: 10.6007/IJAREMS/v2-i4/126

Ciarrochi, J., Deane, F., and Anderson, S. (2002). Emotional intelligence moderates the relationship between stress and mental health. Pers. Individ. Differ. 32, 197-209. doi: 10.1016/S0191-8869(01)00012-5

Ciarrochi, J., Heaven, P. C. L., and Supavadeeprasit, S. (2008). The link between emotion identification skills and socio-emotional functioning in early adolescence: a 1-year longitudinal study. J. Adolesc. 31, 565-582. doi: 10.1016/j.adolescence.2007.10.004 
Clark, P. R. (2004). An Analysis of Emotional Intelligence: Its Relationship to Student Performance and the Implications for Education. Jonesboro, AR: Arkansas State University.

Costa, A., and Faria, L. (2015). The impact of emotional intelligence on academic achievement: a longitudinal study in portuguese secondary school. Learn. Individ. Differ. 37, 38-47. doi: 10.1016/j.lindif.2014.11.011

Davies, M., Stankov, L., and Roberts, R. D. (1998). Emotional intelligence: in search of an elusive construct. J. Pers. Soc. Psychol. 75, 989-1015. doi: 10.1037/0022-3514.75.4.989

DerSimonian, R., and Laird, N. (1986). Meta-analysis in clinical trials. Control. Clin. Trials 7, 177-188. doi: 10.1016/0197-2456(86)90046-2

Di Fabio, A., and Kenny, M. E. (2015). The contributions of emotional intelligence and social support for adaptive career progress among Italian youth. J. Career Dev. 42, 48-59. doi: 10.1177/0894845314533420

Di Fabio, A., and Palazzeschi, L. (2009). An in-depth look at scholastic success: fluid intelligence, personality traits or emotional intelligence? Pers. Individ. Differ. 46, 581-585. doi: 10.1016/j.paid.2008.12.012

Di Fabio, A., and Palazzeschi, L. (2015). Beyond fluid intelligence and personality traits in scholastic success: Trait emotional intelligence. Learn. Individ. Dif. 40, 121-126. doi: 10.1016/j.lindif.2015.04.001

Downey, L. A., Lomas, J., Billings, C., Hansen, K., and Stough, C. (2014). Scholastic success: fluid intelligence, personality, and emotional intelligence. Can. J. Sch. Psychol. 29, 40-53. doi: 10.1177/0829573513505411

Downey, L. A., Mountstephen, J., Lloyd, J., Hansen, K., and Stough, C. (2008). Emotional intelligence and scholastic achievement in Australian adolescents. Aust. J. Psychol. 60, 10-17. doi: 10.1080/00049530701449505

Drati, B. A. (2010). Closing the Achievement Gap: The Relationship between Emotional Intelligence, Race Identity Attitudes, and Academic Achievement with African American Adolescents. Fresno, CA: California State University.

Duncan, S. C., Duncan, T. E., and Strycker, L. A. (2006). Alcohol use from ages 9-16: a cohort-sequential latent growth model. Drug Alcohol Depend 81, 71-81. doi: 10.1016/j.drugalcdep.2005.06.001

Eccles, J. S., and Roeser, R. W. (2009). "Schools, academic motivation, and stageenvironment fit," in Handbook of Adolescent Psychology, 2nd Edn, eds R. M. Lerner and L. Steinberg (Hoboken, NJ: John Wiley \& Sons Inc), 404-434. doi: 10.1002/9780470479193.adlpsy001013

Eryilmaz, A. (2011). A model of subjective well-being for adolescents in high school. J. Happiness Stud. 13, 275-89. doi: 10.1007/s10902-011-9263-9

Fernández-Berrocal, P., Salovey, P., Vera, A., Extremera, N., and Ramos, N. (2005). Cultural influences on the relation between perceived emotional intelligence and depression. Int. Rev. Soc. Psychol. 18, 91-107.

Fernández-Castilla, B., Declercq, L., Jamshidi, L., Beretvas, S. N., Onghena, P., and van den Noortgate, W. (2019). Detecting selection bias in metaanalyses with multiple outcomes: a simulation study. J. Exp. Educ. 8, 1-20. doi: 10.1080/00220973.2019.1582470

Furnham, A., Monsen, J., and Ahmetoglu, G. (2009). Typical intellectual engagement, big five personality traits, approaches to learning and cognitive ability predictors of academic performance. Br. J. Educ. Psychol. 79, 769-782. doi: 10.1348/978185409X412147

Furnham, A., Moutafi, J., and Chamorro-Premuzic, T. (2005). Personality and intelligence: Gender, the big five, self-estimated and psychometric intelligence. Int. J. Sel. Assess. 13, 11-24. doi: 10.1111/j.0965-075X.2005.00296.x

Gannon, N., and Ranzijn, R. (2005). Does emotional intelligence predict unique variance in life satisfaction beyond IQ and personality? Pers. Individ. Differ. 38, 1353-1364. doi: 10.1016/j.paid.2004.09.001

Gil-Olarte Márquez, P., Palomera Martín, R., and Brackett, M. A. (2006). Relating emotional intelligence to social competence and academic achievement in high school students. Psicothema 18(Suppl.), 118-23.

Glickman-Rogers, A. (2010). How do Social and Emotional Competencies Influences the Grades That Male Students Receive? Hempstead, NY: Hofstra University.

Goleman, D. (1995). Emotional Intelligence, Why It Can Matter More than IQ. New York, NY: Bloomsbury Publishing.

Gutman, L., and Schoon, I. (2013). The Impact of Non-cognitive Skills on Outcomes for Young People. London: Education Endowment Foundation, 59

Hedges, L. V., and Olkin, I. (1985). Statistical Methods for Meta-analysis. Academic press.

Herrera, L., Al-Lal, M., and Mohamed, L. (2020). Academic achievement, selfconcept, personality and emotional intelligence in primary education. analysis by gender and cultural group. Front. Psychol. 10:3075. doi: $10.3389 /$ fpsyg.2019.03075

Higgins, J. P. T., and Thompson, S. G. (2002). Quantifying heterogeneity in a meta-analysis. Stat. Med. 21, 1539-1558. doi: 10.1002/sim.1186

Hogan, M., Parker, J., Wiener, J., Watters, C., Wood, L., and Oke, A. (2010). Academic success in adolescence: relationships among verbal IQ, social support and emotional intelligence. Aust. J. Psychol. 62, 30-41. doi: 10.1080/00049530903312881

Johnson, B. (2016). Review article impact of emotional intelligence on academic achievement and leadership. BMH Med. J. 3, 94-99.

Jones, D. P. (2013). The Relationship between Emotional Intelligence and Literacy Achievement of Secondary Students. Minneapolis, MN: Walden University.

Jordan, J. A., McRorie, M., and Ewing, C. (2010). Gender differences in the role of emotional intelligence during the primary-secondary school transition. Emot. Behav. Difficult. 15, 37-47. doi: 10.1080/136327509035 12415

Kaliská, L. (2015). Three types of intelligences and their relationship to students' school performance. New Educ. Rev. 41, 275-286. doi: 10.15804/tner.2015.41.3.22

Khajehpour, M. (2011). Relationship between emotional intelligence, parental involvement and academic performance of high school students. Procedia Soc. Behav. Sci. 15, 1081-1086. doi: 10.1016/j.sbspro.2011. 03.242

Killen, M. A. (2016). The Relationship between Parents' Perceptions of their Child's Emotional Intelligence and Academic Performance among Students with Autism Spectrum Disorder. Minneapolis, MN: Capella University.

Kumar, V. V., Mehta, M., and Maheshwari, N. (2013). Effect of emotional intelligence on the achievement motivation, psychological adjustment and scholastic performance of secondary school students. J. Indian Acad. Appl. Psychol. 39, 60-67.

Kvapil, L. (2007). The Impact of Emotional Intelligence on the Academic Performance of At-Risk High School Students. San Antonio, TX: University of the Incarnate Word.

Lawrence, S. A., and Deepa, T. (2013). Emotional intelligence and academic achievement of high school students in Kanyakumari district. Int. J. Phys. Soc. Sci. 3, 101-107.

Lipsey, W., and Wilson, D. (2000). Practical Meta-Analysis. Thousand Oaks, CA: Sage.

Lui, M. M. (2009). Can I Succeed as an Adolescent Mother? Examining the Role of Emotional Intelligence in Predicting Self-efficacy, Academic Achievement, and School Attendance. Philadelphia, PA: Temple University.

MacCann, C., and Fogarty, G. (2011). Coping mediates the relationship between emotional intelligence (EI) and academic achievement. Contemp. Educ. Psychol. 36, 60-70. doi: 10.1016/j.cedpsych.2010. 11.002

MacCann, C., Jiang, Y., Brown, L. E. R., Double, K. S., and Bucich, M. (2019). Emotional intelligence predicts academic performance: a meta-analysis. Psychol. Bull. 146, 150-186. doi: 10.1037/bul00 00219

Martins, A., Ramalho, N., and Morin, E. (2010). A comprehensive meta-analysis of the relationship between emotional intelligence and health. Pers. Individ. Differ. 49, 554-564. doi: 10.1016/j.paid.2010.05.029

Mateši, K. (2015). The relationship between cognitive and emotional intelligence and high school academic achievement. Coll. Antropol. 39, 371-375.

Mavroveli, S., Petrides, K. V., Shove, C., and Whitehead, A. (2008) Investigation of the construct of trait emotional intelligence in children. Eur. Child Adolesc. Psychiatry 17, 516-526. doi: 10.1007/s00787-0080696-6

Mayer, J. D., Caruso, D., and Salovey, P. (1999). Emotional intelligence meets tradicional standards for an intelligence. Intelligence 27, 267-298. doi: 10.1016/S0160-2896(99)00016-1

Mayer, J. D., and Salovey, P. (1997). What is emotional intelligence? in Emotional Development and Emotional Intelligence: Implications for Educators, eds P. Salovey and D. Sluyter (New York, NY: Basic Books), 3-34.

Mayer, J. D., Salovey, P., and Caruso, D. R. (2002). Mayer-Salovey-Caruso Emotional Intelligence Test (MSCEIT) User's Manual. Toronto, ON: MultiHealth Systems. 
Menzie, T. A. (2005). Emotional Intelligence and Social and Academic Competence in Middle School Youth. New Brunswick, NJ: Rutgers the State University of New Jersey.

Mestre, J. M., Guil, R., Lopes, P. N., Salovey, P., and Gil-Olarte, P. (2006). Emotional intelligence and social and academic adaptation to school. Psicothema 18(Suppl.), 112-117.

Miao, C., Humphrey, R. H., and Qian, S. (2017). A meta-analysis of emotional intelligence and work attitudes. J. Occup. Organ. Psychol. 90, 177-202. doi: 10.1111 /joop. 12167

Mitrofan, N., and Cioricaru, M.-F. (2014). Emotional intelligence and school performance-correlational study. Procedia Soc. Behav. Sci. 127, 769-775. doi: 10.1016/j.sbspro.2014.03.352

Monreal, M. G., and Guitart, M. E. (2012). Some educational concerns grounded in the bronfenbrenner's ecological approach. Univ. Girona 15, 79-92. doi: $10.18172 /$ con.656

Nelson, P. D. (2010). Emotional Intelligence and Academic Achievement in 11th Grade at-Risk Students. Minneapolis, MN: Walden University.

Ogundokun, M., and Adeyemo, D. (2010). "Emotional intelligence and academic achievement; the moderating influence of age, intrinsic and extrinsic motivation," in The African Symposium, Vol. 10 (Nigeria), $127-141$.

Palmer, B., and Stough, C. (2001). Workplace SUEIT: Swinburne University Emotional Intelligence Test-Descriptive Report. Melbourne, VIC: Organizational Psychology Research Unit, Swinburne University.

Parker, J. D. A., Creque, R. E., Barnhart, D. L., Irons, J., Majeski, S. A., Wood, L. M., et al. (2004). Academic achievement in high school: does emotional intelligence matter? Pers. Individ. Differ. 37, 1321-1330. doi: 10.1016/j.paid.2004. 01.002

Pellitteri, J., and Smith, B. (2007). "Building academic success on social and emotional learning: what does the research say?," eds J. E. Zins, R. P. Weissberg, M. C. Wang, and H. J. Walberg Reading Writing Quarterly, Vol. 23 (New York, NY: Teacher College Press), 197-202. doi: 10.1080/10573560600 992837

Perera, H. N., and DiGiacomo, M. (2013). The relationship of trait emotional intelligence with academic performance: a meta-analytic review. Learn. Individ. Differ. 28, 20-33. doi: 10.1016/j.lindif.2013.08.002

Petersen, V. C. (2010). The Relationship between Emotional Intelligence and Middle School Students with Learning Disabilities. Madison, NJ: Fairleigh Dickinson University.

Petrides, K. V. (2009). "Psychometric properties of the trait emotional intelligence questionnaire (TEIQue)," in The Springer Series on Human Exceptionality. Assessing Emotional Intelligence: Theory, Research, and Applications, eds C. Stough, D. H. Saklofske, and J. D. A. Parker (New York, NY: Springer Science + Business Media), 85-101. doi: 10.1007/978-0-387-88370-0_5

Petrides, K. V., Frederickson, N., and Furnham, A. (2004a). The role of trait emotional intelligence in academic performance and deviant behavior at school. Pers. Individ. Differ. 36, 277-293. doi: 10.1016/S0191-8869(03) 00084-9

Petrides, K. V., Furnham, A., and Crawshaw, J. (2004b). Estimates of emotional and psychometric intelligence. J. Soc. Psychol. 144, 149-162. doi: 10.3200/SOCP.144.2.149-162

Pintrich, P., and de Groot, E. (1990). Motivational and self-regulated learning components of classroom academic performance. J. Educ. Psychol. 82, 33-40. doi: 10.1037/0022-0663.82.1.33

Poropat, A. E. (2009). A meta-analysis of the five-factor model of personality and academic performance. Psychol. Bull. 135, 322-338. doi: 10.1037/ a0014996

Pulford, B. D., and Sohal, H. (2006). The influence of personality on HE students' confidence in their academic abilities. Pers. Individ. Differ. 41, 1409-1419. doi: $10.1016 /$ j.paid.2006.05.010

Qualter, P., Gardner, K. J., Pope, D. J., Hutchinson, J. M., and Whiteley, H. E. (2012). Ability emotional intelligence, trait emotional intelligence, and academic success in British secondary schools: a 5 year longitudinal study. Learn. Individ. Differ. 22, 83-91. doi: 10.1016/j.lindif.2011. 11.007

Rice, D. M. (2007). An Examination of Emotional Intelligence: Its Relationship to Academic Achievement in Army JROTC and the Implications for Education. Minneapolis, MN: Capella University.
Ritchie, S. J., and Tucker-Drob, E. M. (2018). How much does education improve intelligence? a meta-analysis. Psychol. Sci. 29, 1358-1369. doi: 10.1177/0956797618774253

Rivers, S. E., Brackett, M. A., Reyes, M. R., Mayer, J. D., Caruso, D. R. and Salovey, P. (2012). Measuring emotional intelligence in early adolescence with the MSCEIT-YV: psychometric properties and relationship with academic performance and psychosocial functioning. J. Psychoeduc. Assess. 30, 344-366. doi: $10.1177 / 0734282912449443$

Rodrigo-Ruiz, D. (2017). Evaluación de la Inteligencia Emocional capacidad en adolescentes españoles: Adaptación y validación del Situactional Test of Emotion Management (STEM). Madrid: UNED.

Saklofske, D. H., Austin, E. J., Mastoras, S. M., Beaton, L., and Osborne, S. E. (2012). Relationships of personality, affect, emotional intelligence and coping with student stress and academic success: different patterns of association for stress and success. Learn. Individ. Differ. 22, 251-257. doi: 10.1016/j.lindif.2011.02.010

Saklofske, D. H., and Zeidner, M. (2006). Springer Series on Human Exceptionality. New York, NY: Springer.

Salovey, P., and Mayer, J. D. (1990). Emotional intelligence. Imagin. Cogn. Personal. 9, 185-211. doi: 10.2190/DUGG-P24E-52WK-6CDG

Sánchez-Álvarez, N., Extremera, N., and Fernández-Berrocal, P. (2016) The relation between emotional intelligence and subjective wellbeing: a meta-analytic investigation. J. Posit. Psychol. 11, 276-285. doi: 10.1080/17439760.2015.1058968

Schneider, T. R., Lyons, J. B., and Khazon, S. (2013). Emotional intelligence and resilience. Pers. Individ. Differ. 55, 909-914. doi: 10.1016/j.paid.2013. 07.460

Schutte, N. S., Malouff, J. M., Hall, L., Haggerty, D., Cooper, J., Golden, C., et al. (1998). Development and validation of a measure of emotional intelligence. Pers. Individ. Differ. 25, 167-177. doi: 10.1016/S0191-8869(98)00001-4

Shen, H., and Comrey, A. (1997). Predicting medical students' academic performances by their cognitives abilities and personality characteristics. Acad. Med. 72, 781-786. doi: 10.1097/00001888-199709000-00013

Team, R. C. (2012). R: A Language and Environment for Statistical Computing. Available online at: http://www.r-project.org/ (accessed April 03, 2013).

Trigueros, R., Aguilar-parra, J. M., Cangas, A. J., Bermejo, R., Ferrandiz, C., and López-Liria, R. (2019). Influence of emotional intelligence, motivation and resilience on academic performance and the adoption of healthy lifestyle habits among adolescents. Int. J. Environ. Res. Public Health 16:2810. doi: $10.3390 /$ ijerph 16162810

Usán Supervía, P., and Salavera Bordás, C. (2018). Motivación escolar, inteligencia emocional y rendimiento académico en estudiantes de Educación Secundaria Obligatoria. Actual. en Psicol. 32:95. doi: 10.15517/ap.v32i125. 32123

Usán, P., and Salavera, C. (2019). El rendimiento escolar, la inteligencia emocional y el engagement académico en adolescentes. Electron. J. Res. Educ. Psychol. 17, 5-26. doi: 10.25115/ejrep.v17i47.1879

Vidal Rodeiro, C. L., Emery, J. L., and Bell, J. F. (2012). Emotional intelligence and academic attainment of British secondary school children: a crosssectional survey. Educ. Stud. 38, 521-539. doi: 10.1080/03055698.2011. 643115

Viechtbauer, W. (2010). Conducting meta-analysis in R with the metafor package. J. Stat. Softw. 36, 1-48. doi: 10.18637/jss.v036.i03

Ward, A., Stoker, H. W., and Murray-Ward, M. (1996). Achievement and ability tests-definition of the domain. Educ. Meas. 2, 2-5.

Woitaszewski, S. A., and Aalsma, M. C. (2004). The contribution of emotional intelligence to the social and academic success of gifted adolescents as measured by the multifactor emotional intelligence scale - adolescent version. Roeper Rev. 27, 25-30. doi: 10.1080/02783190409554285

Wong, C. S., and Law, K. S. (2002). The effects of leader and follower emotional intelligence on performance and attitude: an exploratory study. Leadersh. Q. 13, 243-274. doi: 10.1016/S1048-9843(02)00099-1

$\mathrm{Xu}$, J. (2018). Emotion regulation in mathematics homework : an empirical study. J. Educ. Res. 111, 1-11. doi: 10.1080/00220671.2016. 1175409

Zeidner, M., and Matthews, G. (2016). Ability emotional intelligence and mental health: social support as a mediator. Pers. Individ. Differ. 99, 196-199. doi: $10.1016 / j$.paid.2016.05.008 
Zeidner, M., Matthews, G., and Roberts, R. D. (2012). The emotional intelligence, health, and well-being nexus: what have we learned and what have we missed? Appl. Psychol. Heal. Well-Being 4, 1-30. doi: 10.1111/j.1758-0854.2011.01062.x

Conflict of Interest: The authors declare that the research was conducted in the absence of any commercial or financial relationships that could be construed as a potential conflict of interest.
Copyright (C) 2020 Sánchez-Álvarez, Berrios Martos and Extremera. This is an openaccess article distributed under the terms of the Creative Commons Attribution License (CC BY). The use, distribution or reproduction in other forums is permitted, provided the original author(s) and the copyright owner(s) are credited and that the original publication in this journal is cited, in accordance with accepted academic practice. No use, distribution or reproduction is permitted which does not comply with these terms. 
APPENDIX

TABLE A1 | Studies included in the meta-analysis of the relationships between El and AP.

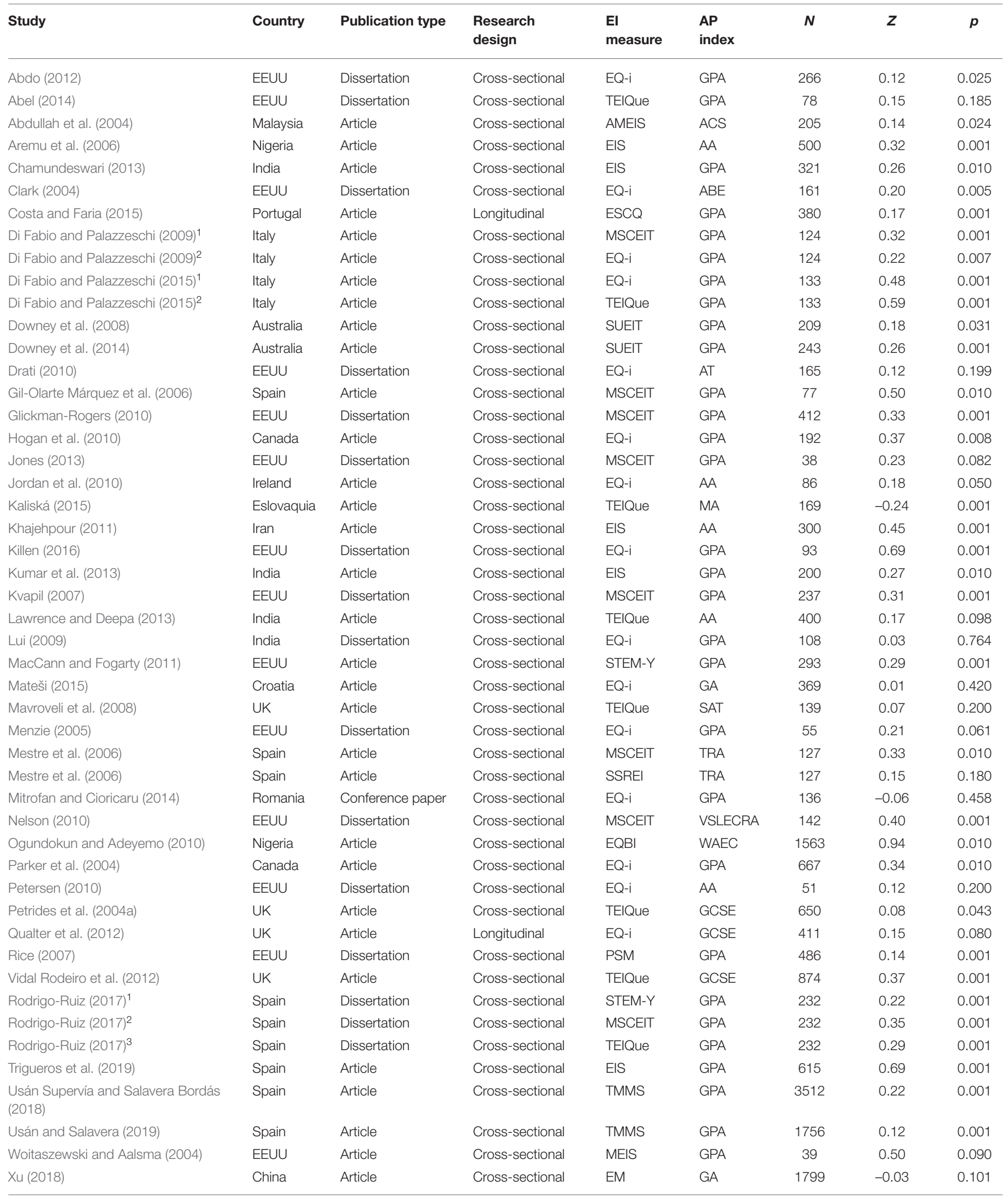

${ }^{1}$ First instrument used, ${ }^{2}$ second instrument used, ${ }^{3}$ third instrument useds. 